\title{
A Community-Based Study on Waist-to-Height Ratio: An Indicator for Systolic Hypertension in a Rural Community of Hilly Region
}

\author{
Santosh Kumar ${ }^{1}$, Ravi Kant ${ }^{2,} 3$, Poonam Yadav ${ }^{3}$, Kavitha Natarajan ${ }^{4}$, Yogesh Bahurupi ${ }^{1}$, Ashutosh \\ Mishra ${ }^{1}$ \\ 1. Community and Family Medicine, All India Institute of Medical Sciences, Rishikesh, Rishikesh, IND 2. General \\ Medicine, All India Institute of Medical Sciences, Rishikesh, Rishikesh, IND 3. College of Nursing, All India Institute of \\ Medical Sciences, Rishikesh, Rishikesh, IND 4. Physiology, Jawaharlal Institute of Postgraduate Medical Education and \\ Research, Puducherry, IND
}

Corresponding author: Poonam Yadav, dryadavpoonam257@gmail.com

\begin{abstract}
The prevalence of hypertension gradually becomes a serious public health threat as it is a very pertinent risk factor for cardiovascular and cerebrovascular diseases. This study aims to estimate the prevalence of isolated systolic hypertension (ISH) among the hilly region's rural community and identify the indicators of ISH among study participants. A community-based cross-sectional study was conducted among 1220 participants in the rural community of the hilly region. A multistage random sampling technique was applied to recruit the participants. Demographic and anthropometric dimensions were measured to analyze the outcome of the study. The participants' mean age was $44.42 \pm 15.54$ years, with a majority of 822 female participants $(67.40 \%)$. The prevalence of ISH was found as $27.45 \%$. A statistically significant positive correlation ( $p<$ 0.05) of the waist-to-height ratio (WHtR) and body mass index (BMI) were observed with systolic blood pressure (SBP) in male as well as female participants, whereas BMI and WHtR had no correlation with diastolic blood pressure (DBP). Among female participants, the area under the curve (AUC) for BMI and WHtR was 0.604 ( $95 \%$ confidence interval 0.565-0.643, $p$-value $=0.020^{*}$ ) and 0.622 ( $95 \%$ confidence interval $0.584-0.660$, p-value $=0.020 *$, respectively. Among male participants, the AUC for BMI and WHtR was 0.574 and 0.592 , respectively. Hence, it cannot be considered very satisfactory. The increasing prevalence of ISH in a rural community is also a public health concern. At the preliminary stage, anthropocentric measurements are the primary tool for a family physician while treating the patients. This study concluded that WHtR is a better indicator than BMI for systolic hypertension. Although we have not observed a strong correlation of WHtR with systolic hypertension, it is required to perform future research to support this study's evidence.
\end{abstract}

Review began 06/09/2021 Review ended 06/19/2021 Published 06/29/2021

๑) Copyright 2021

Kumar et al. This is an open access article distributed under the terms of the Creative Commons Attribution License CC-BY 4.0., which permits unrestricted use, distribution, and reproduction in any medium, provided the original author and source are credited.
Categories: Endocrinology/Diabetes/Metabolism, Family/General Practice, Public Health

Keywords: body mass index, diastolic blood pressure, obesity, systolic blood pressure, waist to height ratio

\section{Introduction}

Disease burden and associated risk factors have shifted significantly from communicable to noncommunicable diseases (NCD) universally in the past two decades. Chronic NCDs are assuming increased importance among adults in both developing and developed countries. The increasing prevalence of hypertension gradually becomes a serious public health threat among NCDs as it is a very pertinent risk factor for cardiovascular and cerebrovascular diseases [1]. Isolated systolic hypertension (ISH) happens due to vascular tree elasticity, resulting in aggravation in SBP and normal DBP elasticity of vessels relevant in younger age groups [2]. Arterial stiffness/elasticity and stroke volume play a role in increasing the systolic blood pressure (SPB), pulse pressure amplification, and stroke volume, which was reported moderately higher in patients with ISH [2].

Many environmental and genetic factors are responsible for hypertension, such as gender, age, body mass index (BMI), diet, stress, physical activity, tobacco, and alcohol consumption. Among these factors, obesity, metabolic syndrome, and hereditary factors are important factors predisposing to hypertension. Many people go undiagnosed of hypertension because it rarely causes symptoms at the earlier stages, and people who are diagnosed may not have access to treatment, resulting in their inability to control their hypertension over a long time successfully. Approximately 17 million deaths contribute to cardiovascular disease in a year globally, which was nearly one-third of total deaths, and 9.4 million deaths account for only complications of hypertension worldwide every year. If hypertension were addressed and treated adequately at the earlier stage, there would be a significant social and economic impact [3].

A variety of anthropometric parameters such as BMI, waist circumference (WC), waist-to-height ratio (WHtR), and waist-hip ratio (WHR) are used for screening abdominal fat or total fat to assess risk for hypertension [4]. Central fat distribution has higher risks than those with peripheral fat in the risk population [5]. 
Hypertension is an iceberg disease, and scarcity of disease sometimes is misunderstood as the non-existence of the disease. After understanding modifiable risk factors' role, anthropometric parameters are the key to developing a clear and effective screening strategy in the community [6]. Assessment of risk of hypertension requires identification of a straightforward tool that can be used by a health worker in the screening program in the community. This study aims to assess the prevalence of ISH and its predictors in the study population of rural community settings of hilly regions.

\section{Materials And Methods}

\section{Study setting}

A cross-sectional study was conducted in Uttarakhand, also known as the "Indian central Himalayan region." Uttarakhand is known for the high glacier of the Himalayas, with Nepal to the east, Himachal Pradesh near the West and northwest, and the Tibet region of China toward the north. Rishikesh is one of the six tehsils in the Dehradun district of Uttarakhand known as "Gateway to the Garhwal Himalayas" and "Yoga Capital of the World.” It lays approximately $25 \mathrm{kms}$ from Haridwar and $43 \mathrm{kms}$ from Dehradun, having an area of $500.73 \mathrm{~km}^{2}$. As per the 2011 census, Rishikesh has a population of 2,60,343 and 54,517 households. There are seven towns and 87 villages in Rishikesh Tehsil.

\section{Study period}

Data were collected from May 2018 to May 2019.

\section{Study design}

A community-based cross-sectional study was conducted from rural Rishikesh, Uttarakhand.

\section{Sample size}

Considering the previous prevalence of ISH (10.5\%) by the Indian Council of Medical Research-India Diabetes (ICMR-INDIAB) study with a $95 \%$ confidence level, the relative precision of $20 \%$ of prevalence minimum sample size was 900 . Since multistage random sampling was used, a design effect of 1.2 was applied to reduce biases.

$\mathrm{n}=\mathrm{Z} 2 \mathrm{p}(1-\mathrm{p}) / \mathrm{L} 2$

where:

$\mathrm{n}=$ Sample size

$\mathrm{Z}=1.96$

$\mathrm{p}=$ Prevalence (from previous studies)

$\mathrm{L}=$ Allowable error

The sample size was estimated to be 1080 , but 1220 study participants were included in the study.

\section{Inclusion criteria}

Adults aged from 18 to 90 years were included.

\section{Exclusion criteria}

Those who were pregnant, mentally ill, bedridden, seriously ill, having cardiovascular morbidity, stroke, and on hypertensive treatment were excluded from this study, and the person not willing to give consent was also included in the exclusion criteria.

\section{Sampling technique}

In this study, a multistage random sampling technique was used to recruit the participants. Rishikesh Tehsil was selected randomly among six tehsils of Dehradun district (Dehradun, Vikasnagar, Rishikesh, Chakrata, Kalsi, Tyuni) for this study. After selecting Rishikesh as the study area list of Rishikesh villages, there were 87 villages in Rishikesh as per the 2011 census. Using two-stage cluster random sampling and probability proportional to size, we selected 10 villages or clusters of 87 villages of Rishikesh Tehsil to obtain the desired sample for this study. We ensured that all persons in the sampling area had a similar probability of getting selected irrespective of their cluster, and from each cluster, the same number of persons had to be sampled. 
was prepared. Subsequently, the sampling interval (SI) was calculated by dividing the total cumulative population, one lakh thirty-seven thousand nine hundred and forty-three $(1,37,943)$, by the number of clusters desired in the sample, which was 10 in number. Therefore, the SI obtained was 13794.3. A random number was generated from the cumulative population range, which was 7381 , with the generation of random number first cluster selected for the study by matching the random number to the cumulative population, which was either equal to or exceeded the random number value. Subsequent clusters or villages were selected by adding a random start number (RS) to the SI. (second cluster $=$ RS + SI, third cluster $=$ RS + $2 *$ SI, fourth cluster $=$ RS $+3 *$ SI, and so on). Athhoorwala, Bhogpur, Harrawala, Rishikesh, Jauligrant, Jeevan Wala, Khandraiwala, Mazri Grant, Rani Pokhari grant, and Shyampur were 10 villages or clusters selected for this study.

In the second stage of cluster sampling, individuals from each cluster were recruited using a simple random sampling method (lottery method). Total individuals selected from each cluster were 122 in number, and finally, we included 1220 individuals for this study from Rishikesh Tehsil.

\section{Data collection}

Informed consent was obtained from participants, and a pre-tested questionnaire was used to collect the data. Confidentiality of information was ensured to participants. Anthropometric dimensions like weight (kilograms) in a digital weighing scale, height (centimeter) in stadiometer, WC, and hip circumference (HC) (centimeter) using standard World Health Organization (WHO) protocols were measured. To get the detailed anthropometric indices, height (close to $0.001 \mathrm{~m}$ ) and bodyweight (close to $0.1 \mathrm{~kg}$ ) were documented in participants without shoes and only with light indoor clothes. The WC was measured between the lowermost border of the ribs and the iliac crest. The buttocks' maximum measured circumference will be the $\mathrm{HC}$, the persons standing with feet placed together. Blood pressure was measured as per standard WHO protocol by using a mercury-free sphygmomanometer. Before the blood pressure measurement, participants were asked to relax for five minutes and then asked to sit in a relaxed position, with back supported, uncrossed legs with the bared upper arm. The arm needs to be supported at heart level. The cuff bladder was encircled $80 \%$ or more of the participant's arm circumference. The mercury-free column was deflated at 2-3 $\mathrm{mm}$ per second. The first and last audible sound was recorded as systolic and diastolic pressure, respectively. Both the participants and investigator did not talk during the measurement of blood pressure.

Blood pressure was recorded twice. The intervals between the two recordings were one minute, and the mean of the measurements was recorded. The first reading in a series is usually the highest. Additional readings were taken if the difference between the first two was found greater than $5 \mathrm{mmHg}$.

\section{Operational definitions}

ISH: When SBP is $\geqslant 140 \mathrm{mmHg}$ and diastolic blood pressure (DBP) is $<90 \mathrm{mmHg}$ [7].

For Asian populations, recent classification of BMI $\left(\mathrm{kg} / \mathrm{m}^{2}\right)$ was used to define "overweight (23-24.99 $\mathrm{kg} / \mathrm{m}^{2}$ )" and "obesity (>25 kg/m²)" [8]. Waist-to-height ratio (WHtR) defined as "WHtR < 0.5 (no risk), WHtR $\geqslant 0.5<0.6$ (increased risk), and (WHtR $\geqslant 0.6$ (very high risk)” [9].

\section{Data analysis}

Collected data was shifted to Statistical Package for the Social Sciences (SPSS) version 23.0 (IBM Corp., Armonk, NY), which was used for data analysis. Continuous variables were described as mean and standard deviation in the table. For categorical variables, cross-tabulation and frequency distribution were done. A Chi-square test was applied to determine association. Pearson's correlation was applied to find out the correlation of ISH with anthropometric measures. In the receiver operating characteristic (ROC) curve, AUC was drawn to find out the best indicator for diagnosing hypertension. P-value was considered significant as $<0.05$.

\section{Results}

The study population's mean age was $44.42 \pm 15.54$ years (males: $43.51 \pm 17.43$ years and females: $44.85 \pm$ 14.525 years), with the majority of female participants as $67.40 \%(822 / 1220)$. The mean BMI among male and female participants was $25.690 \pm 4.79$ and $26.78 \pm 5.005$, respectively. The majority of the study population, $59.90 \%$ (731), belongs to the lower class, followed by the lower middle class, $31.10 \%$ (380), and 7.70\% belong to the upper class. We also found a significant association of age, gender, and socioeconomic status with ISH $\left(\mathrm{p}\right.$-value $\left.<0.01^{* * *}\right)($ Table 1$)$. 


\section{Cureus}

\begin{tabular}{|c|c|c|}
\hline Variables & Frequency (\%) & P-valu \\
\hline Age (Mean \pm SD) & $44.42 \pm 15.54$ & 0.001 \\
\hline$<25$ yrs & $169(13.8)$ & \\
\hline $25-50$ yrs & 603 (49.4) & \\
\hline 50-75 yrs & $417(34.2)$ & \\
\hline$>75$ yrs & $31(2.6)$ & \\
\hline Gender & & 0.003 \\
\hline Male & $398(32.60)$ & \\
\hline Female & $822(67.40)$ & \\
\hline Socioeconomic status & & 0.000 \\
\hline Lower class & $731(59.90)$ & \\
\hline Upper lower class & $14(1.10)$ & \\
\hline Lower middle class & $380(31.10)$ & \\
\hline Upper middle class & $1(0.10)$ & \\
\hline Upper class & $94(7.70)$ & \\
\hline Education & & 0.064 \\
\hline Primary education & $247(20.2)$ & \\
\hline Up to higher education & $300(24.6)$ & \\
\hline Graduation and post-graduation & $585(48)$ & \\
\hline Professional education & $88(7.2)$ & \\
\hline Marital status & & 0.56 \\
\hline Married & $536(43.9)$ & \\
\hline Unmarried & 677 (55.5) & \\
\hline Others & $7(0.6)$ & \\
\hline
\end{tabular}

TABLE 1: Demographic characteristics of participants and their association with isolated systolic hypertension $n=1220$

Among them, 122 (10\%) were known as diabetic, 85 (7\%) were known as hypertensive, and 68 (5.60\%) were on previous medication for diabetes and hypertension. The prevalence of ISH in the present study is $27.45 \%$. We found a significant association of WHtR ( $p$-value $<0.01^{* * *}$ ) and BMI (p-value $<0.01^{* * * *}$ ) with ISH (Table 2). 


\section{Cureus}

Variables

Frequency $(\%)$

P-value

Isolated systolic hypertension

Yes

No

BMI

$23-24.99 \mathrm{~kg} / \mathrm{m}^{2}$

$>25 \mathrm{~kg} / \mathrm{m}^{2}$

Waist-to-height ratio

$<0.5$

$0.5-0.6$

$>0.6$

On medication

Yes

No

Diabetes

Yes

No

Chi-square test, p-value significant $<0.05^{\star},<0.01^{\star *}$
335 (27.45)

$885(72.55)$

0.003

536 (44)

$684(56)$

0.000

251 (20.6)

791 (64.8)

178 (14.6)

0.000

$68(5.4)$

$1152(94.6)$

0.000

$122(10.1)$

$1098(90.9)$

TABLE 2: Association of clinical variables of participants with isolated systolic hypertension $\mathbf{n}=$ 1220

BMI, Body mass index.

Summary of continuous variables such as weight, height, WC, SBP, diastolic blood pressure (DBP), and pulse rate has been shown with mean and standard deviation in Table 3. 


\section{Cureus}

\begin{tabular}{|c|c|c|}
\hline & Male & Female \\
\hline Variables & Mean \pm SD & \\
\hline Age & $43.51 \pm 17.436$ & $44.85 \pm 14.525$ \\
\hline Weight & $63.01 \pm 9.422$ & $62.08 \pm 9.44$ \\
\hline Height & $157.51 \pm 10.956$ & $152.92 \pm 7.953$ \\
\hline Waist circumference & $84.82 \pm 7.309$ & $83.51 \pm 7.488$ \\
\hline Systolic BP & $129.51 \pm 19.293$ & $128.88 \pm 19.523$ \\
\hline Diastolic BP & $78.08 \pm 10.966$ & $77.12 \pm 10.206$ \\
\hline Pulse rate & $74.95 \pm 6.826$ & $75.79 \pm 7.346$ \\
\hline Waist-to-height ratio & $0.5406 \pm 0.05486$ & $0.5475 \pm 0.05536$ \\
\hline BMI & $25.6904 \pm 4.7958$ & $26.7892 \pm 5.00568$ \\
\hline
\end{tabular}

TABLE 3: Summary of continuous variables $n=1220$

BMI, Body mass index.

The BMI among female participants was higher compared to male participants. The mean WHtR among the study population was $0.540 \pm 0.054$ for males and $0.547 \pm 0.055$ for females.

SBP was significantly positively correlated (p-value $<0.01 * *$ ) with WHtR and BMI among male and female participants, whereas BMI and WHtR had statistically insignificant $(p>0.05)$ and poor correlation with DBP among both males and females found (Table 4 ). 


\section{Cureus}

Pearson's Correlation for Males

\begin{tabular}{|c|c|c|}
\hline Variables & BMI (r-Value) & Waist Height Ratio (r-Value) \\
\hline Weight & $0.700^{\star \star}$ & 0.095 \\
\hline Height & $-0.616^{\star \star}$ & $-0.552^{\star \star}$ \\
\hline Waist circumference & 0.059 & $0.758^{\star \star}$ \\
\hline Systolic BP & $0.368^{\star \star}$ & $0.354^{\star \star}$ \\
\hline Diastolic BP & 0.054 & 0.012 \\
\hline Pulse rate & -0.067 & -0.084 \\
\hline \multicolumn{3}{|c|}{ Pearson's Correlation for Females } \\
\hline Weight & $0.852^{\star \star}$ & $0.231^{\star \star}$ \\
\hline Height & $-0.594^{\star \star}$ & $-0.469^{\star \star}$ \\
\hline Waist circumference & $0.143^{\star \star}$ & $0.865^{\star \star}$ \\
\hline Systolic BP & $0.373^{\star \star}$ & $0.342^{\star \star}$ \\
\hline Diastolic BP & 0.002 & 0.035 \\
\hline Pulse rate & -0.007 & -0.003 \\
\hline
\end{tabular}

TABLE 4: Correlation of clinical variables with BMI and waist-to-height ratio among male and female participants

BMI, Body mass index.

Among female participants, the area under the curve (AUC) for BMI and WHtR was 0.604 (standard error: 26.3741, 95\% confidence interval 0.565-0.643, p-value $=0.020 \%$ and 0.622 (standard error: $0.5516,95 \%$ confidence interval 0.584-0.660, p-value $=0.020$ ), respectively. Among male participants, the AUC for BMI and WHtR was 0.574 (standard error: 25.6445 , 95\% confidence interval $0.515-0.632$, p-value $=0.030^{*}$ ) and 0.592 (standard error: $0.5467,95 \%$ confidence interval $0.534-0.650$, p-value $=0.030 *$ ), respectively. ROC curve indicated that WHtR can be the better indicator for diagnosing the hypertension than BMI among study participants (Figure 1). 


\section{Cureus}

ROC Curve

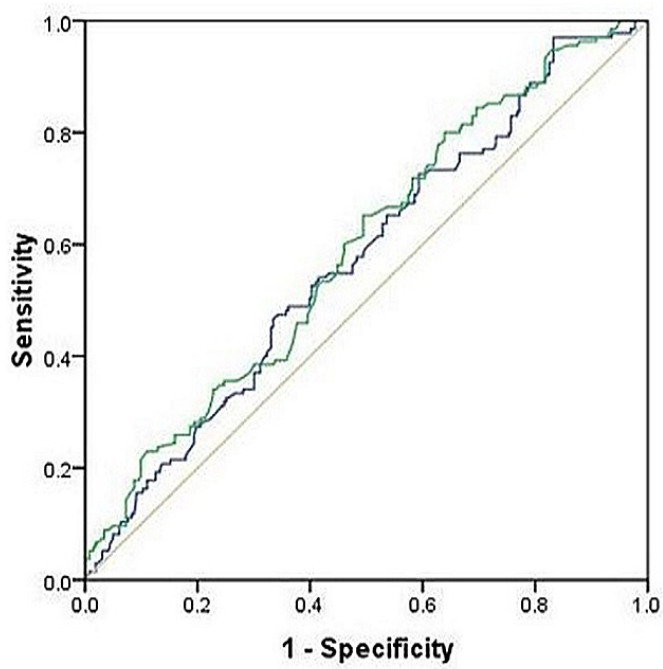

Source of the Curve - BMI

- Waist-height ratio - Reference Line

Diagonal segments are produced by ties.

\section{(A)Among male participants}

ROC Curve

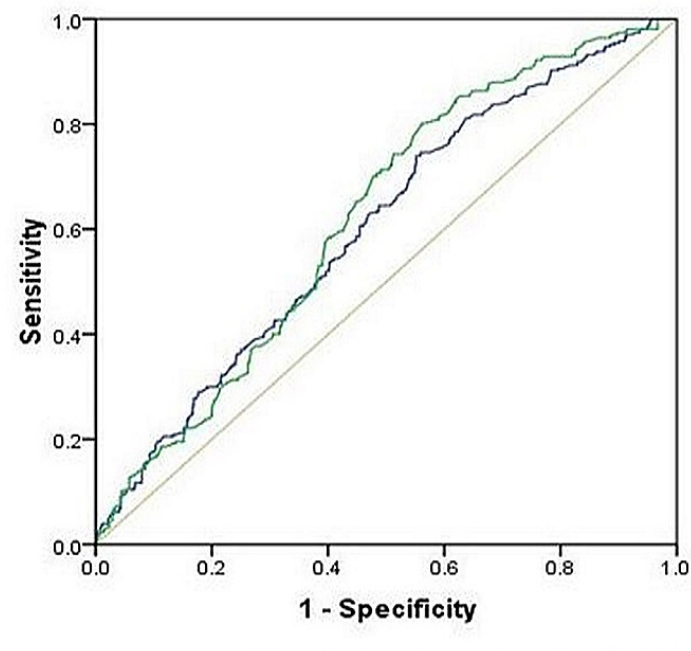

Source of the Curve - BIMI Waist-height ratio Reference Line

Diagonal segments are produced by ties.

\section{(B) Among female participants}

FIGURE 1: ROC curve for anthropometric parameter with systolic hypertension among participants

ROC, Receiver operating characteristic curve.

\section{Discussion}

The mortality and morbidity due to hypertension are rising among adults, especially in developing countries. This study was conducted among 1220 people residing in the rural hilly region of Uttarakhand. In the present study, the prevalence of ISH is $27.45 \%$. A study conducted at the Lucknow district of North India in 2010 found that the prevalence of ISH among the young population was $4.5 \%$, which is relatively lower than the present study [10]. Consistently, Malhotra et al. reported the prevalence of hypertension as $4.5 \%$ (JNC V [Joint National Committee on the Prevention, Detection, Evaluation, and Treatment of High Blood Pressure] criteria $\mathrm{BP} \geqslant 140 / 90 \mathrm{mmHg}$ ) in a rural population of Haryana, North India, which has a similar geographical 
pattern to our study setting [11]. Kishore et al.'s study in India's capital region found that the prevalence of hypertension is $14.1 \%$, higher in participants who are more than 35 years old than those who are less than 35 years old [12]. Nevertheless, it was relatively less than a study conducted in the north region, Chandigarh, where the prevalence of hypertension was $29.0 \%$, consistent with the present study [13].

The total burden of type 2 diabetes mellitus (T2DM) in the present study was measured as $10 \%$, comparable to various other studies as $8.03 \%$ and $7.5 \%$ of prevalence $[14,15]$. The variation in the prevalence could be explained by differences in age, geographical distribution, cultural practices, diet, sociodemographic pattern, alcohol, and tobacco consumption among the study population. In contrast to our findings, a survey conducted by Tripathy et al. reported the prevalence of isolated hypertension as $40.1 \%$, higher than the present study [16].

The mean age of study participants in this study was $44.42 \pm 15.54$ years (males: $43.51 \pm 17.43$ years, females: $44.85 \pm 14.52$ years). It is comparable to the previous study conducted in Mysore, where the study subjects' mean age was $47.27 \pm 10.31$ years [17]. The mean SBP in the present study was $129.08 \pm 19.44 \mathrm{mmHg}$ (males: $129.51 \pm 19.29 \mathrm{mmHg}$, females: $128.88 \pm 19.52 \mathrm{mmHg}$ ). The mean DBP in the current study was $77.43 \pm 10.4$ $\mathrm{mmHg}$ (males: $78.08 \pm 10.96 \mathrm{mmHg}$, females: $77.12 \pm 10.20 \mathrm{mmHg}$ ) with no statistically significant difference between both the gender. This was comparable to the previous study conducted in Varanasi, India, where the mean SBP and DBP were $124.2 \pm 15.0$ and 83.4 \pm 9.5 , respectively [18]. Unlike our study, Singh et al. found a statistically significant difference for SBP and DBP between genders [18]. This variation may be described as urbanization, such as lifestyle changes and the participants' dietary patterns.

A previous study was conducted among the Punjab community residing in Delhi where the mean height among males and females was $166.2 \pm 15.43 \mathrm{~cm}$ and $155.7 \pm 5.78 \mathrm{~cm}$, respectively, and the mean weight among the study population males and females was $67.8 \pm 14.14 \mathrm{kgs}$ and $63.2 \pm 54.10 \mathrm{kgs}$, respectively, which were similar to the present study [19]. A study performed by Midha et al. found that the mean WC was $76.5 \pm$ 11.3 (males: $78.9 \pm 11.0$ and females: $74.4 \pm 11.1$ ), which is consistent with our findings [20]. Huang et al. observed the mean pulse rate among study populations as $70.0 \pm 9.0$ beats per min, comparable to our study [21]. In the present study, females were found to have a higher BMI than males. Consistently, Dua et al. performed a study in the Capital Region of India and found that female participants had a higher BMI (27.7 \pm 4.60) than male participants $(25.8 \pm 17.6)$ [19]. Concurrently, the mean WHtR (male: $0.547 \pm 0.054$ and female: $0.5475 \pm 0.055$ ) among study participants was similar to the study conducted by Verma et al. in Chandigarh, India. In that study, the WHtR (males: $0.054 \pm 0.05$; females: $0.55 \pm 0.08$ ) was indicated as a potent risk factor for hypertension [13].

In the present study, BMI and WHtR were positively correlated with systolic hypertension ( $\mathrm{SH}$ ) in male and female participants, whereas BMI and WHtR were not statistically significantly correlated with DBP in male or female participants. Consistently, Tesfaye et al. reported a positive correlation of SBP and DBP with BMI among population subgroups of Asia and Africa [22]. Kim et al. observed a positive correlation of SBP with WHtR, BMI, and body fat \% among Korean adolescents [23]. As short stature is found to be the probable cause of the positive correlation between anthropometric measurements and SBP, height is known to be a strong indicator for the nutritional assessment at an early stage of life, and nutrition deficiency with short stature may predispose individuals to various metabolic changes in an organ system, cell structures, and physiology, which consequently leads to the obesity [24]. Anthropometric measurements were found to be associated with high screening parameters for an increase in blood pressure.

In contrast, Song et al. explained that BMI maintained a positive association with SBP and DBP [25]. In another study by Tawfik et al., where blood pressure was correlated with BMI, WHtR, and WC and SH, it was highly significant in patients with high WHtR but not significant with WC and BMI [26]. In calculating WHtR, height is an essential factor as short stature contributes to obesity and hypertension [27]. The mean height in the Indian population is $164.7 \mathrm{~cm}$, whereas the mean height of the study participants is $154 \mathrm{~cm}$ in the present study. This difference may be the probable cause of the association of SH with WHtR. In ROC, an AUC for WHtR was 0.592 and for BMI was 0.514 , which concluded that WHtR could be a better indicator for diagnosing hypertension than BMI among the study population in the present study, which could be substantiated with results of previous studies [28-30].

Adults who were found to have higher blood pressure values need to be followed up subsequently to treat and prevent associated complications. Factors such as salt intake, physical activity, tobacco, alcohol consumption, familial predisposition, and eating habits would be relevant for future surveys among hypertensive patients. Prevention of cardiovascular and cerebrovascular risk factors among hypertensive should be done as early as possible. Primordial prevention could be the only strategy to prevent NCDs in the community, mainly when resources are scarce. This study re-emphasizes the need to develop a preventive, promotive, and comprehensive plan to reduce hypertension by empowering the policymakers to realize the need for increased physical activity, healthy dietary habits, and lifestyle modification.

\section{Strength of the study}

It was a large-scale community-based study representing different age groups and socioeconomic strata in rural and hilly regions. 
Prevalence of SH and their association between WHtR and BMI in the study population would reflect the increased prevalence of hypertension and related disorders as the obesity epidemic may further grow.

\section{Limitation of the study}

In the present study, environmental and occupational factors were not correlated with SH.

\section{Conclusions}

The increasing prevalence of ISH among rural communities is also a public health challenge. Among obesity indicators, WHtR might be used as an initial screening tool for the risk of hypertension among adults due to its ease of measurement. A positive correlation between BMI and SH also indicates that lifestyle modification measures need to be adopted. Although a strong correlation of WHtR with SH was not noted hence, it is required to perform future research to support this study's evidence. Prevention and control of hypertension are complex processes. Therefore, multiple collaborations with the government, private sectors, and community should be made to reduce the risk of hypertension and its life-threatening complications.

\section{Additional Information \\ Disclosures}

Human subjects: Consent was obtained or waived by all participants in this study. Institutional Ethical Committee, All India Institute of Medical Sciences, Rishikesh, India issued approval ECR/736/inst/UK/2015. Ethical permission was taken from the Institutional Ethical Committee. The ethical approval number is ECR/736/inst/UK/2015. Animal subjects: All authors have confirmed that this study did not involve animal subjects or tissue. Conflicts of interest: In compliance with the ICMJE uniform disclosure form, all authors declare the following: Payment/services info: All authors have declared that no financial support was received from any organization for the submitted work. Financial relationships: All authors have declared that they have no financial relationships at present or within the previous three years with any organizations that might have an interest in the submitted work. Other relationships: All authors have declared that there are no other relationships or activities that could appear to have influenced the submitted work.

\section{References}

1. Non communicable diseases. (2012). Accessed: December 12, 2020: https://www.who.int/news-room/factsheets/detail/noncommunicable-diseases.

2. McEniery CM, Franklin SS, Cockcroft JR, Wilkinson IB: Isolated systolic hypertension in young people is not spurious and should be treated: pro side of the argument. Hypertension. 2016, 68:269-75. 10.1161/HYPERTENSIONAHA.116.06547

3. A global brief on hypertension: silent killer, global public health crisis: World Health Day 2013 . (2013). Accessed: August 6, 2019: https://apps.who.int/iris/handle/10665/79059.

4. Zhang Q, Mahapatra T, Huang F, et al.: Association between anthropometric measures and indicators for hypertension control among Kazakh-Chinese hypertension patients in Xinjiang, China: results from a crosssectional study. PLoS One. 2017, 12:e0170959. 10.1371/journal.pone.0170959

5. Lebovitz HE, Banerji MA: Point: visceral adiposity is causally related to insulin resistance. Diabetes Care. 2005, 28:2322-5. 10.2337/diacare.28.9.2322

6. Vaidya A, Pokharel PK, Karki P, Nagesh S: Exploring the iceberg of hypertension: a community based study in an eastern Nepal town. Kathmandu Univ Med J (KUMJ). 2007, 5:349-59.

7. Liu X, Rodriguez CJ, Wang K: Prevalence and trends of isolated systolic hypertension among untreated adults in the United States. J Am Soc Hypertens. 2015, 9:197-205. 10.1016/j.jash.2015.01.002

8. WHO Expert Consultation: Appropriate body-mass index for Asian populations and its implications for policy and intervention strategies. Lancet. 2004, 363:157-63. 10.1016/S0140-6736(03)15268-3

9. Ashwell M, Gibson S: Waist-to-height ratio as an indicator of 'early health risk': simpler and more predictive than using a 'matrix' based on BMI and waist circumference. BMJ Open. 2016, 6:e010159. 10.1136/bmjopen2015-010159

10. Midha T, Idris M, Saran R, Srivastava A, Singh S: Isolated systolic hypertension and its determinants - a cross-sectional study in the adult population of Lucknow district in North India. Indian J Community Med. 2010, 35:89-93. 10.4103/0970-0218.62579

11. Malhotra P, Kumari S, Kumar R, Jain S, Sharma BK: Prevalence and determinants of hypertension in an unindustrialised rural population of North India. J Hum Hypertens. 1999, 13:467-72. 10.1038/sj.jhh.1000864

12. Kishore J, Gupta N, Kohli C, Kumar N: Prevalence of hypertension and determination of its risk factors in rural Delhi. Int J Hypertens. 2016, 2016:7962595. 10.1155/2016/7962595

13. Verma S, Jain KK, Sahu D, Panda PS: Prevalence, awareness, treatment and control of hypertension among adults of Raipur city, Chhattisgarh, India: a cross sectional study. Int J Res Med Sci. 2016, 4:4089-92. 10.18203/2320-6012.ijrms20162939

14. Singh PS, Sharma H, Zafar KS, et al.: Prevalence of type 2 diabetes mellitus in rural population of India - a study from western Uttar Pradesh. Int J Res Med Sci. 2017, 5:1363-7. 10.18203/2320-6012.ijrms20171227

15. Geldsetzer P, Manne-Goehler J, Theilmann M, et al.: Diabetes and hypertension in India: a nationally representative study of 1.3 million adults. JAMA Intern Med. 2018, 178:363-72. 10.1001/jamainternmed.2017.8094

16. Tripathy JP, Thakur JS, Jeet G, Chawla S, Jain S: Alarmingly high prevalence of hypertension and pre- 
hypertension in North India-results from a large cross-sectional STEPS survey. PLoS One. 2017, 12:e0188619. 10.1371/journal.pone.0188619

17. Marinayakanakoppalu RR, Nagaralu AC: A study of prevalence of hypertension among urban and rural population and the factors associated with hypertension. Ntl J Community Med. 2017, 8:57-62.

18. Singh S, Shankar R, Singh GP: Prevalence and associated risk factors of hypertension: a cross-sectional study in urban Varanasi. Int J Hypertens. 2017, 2017:5491838. 10.1155/2017/5491838

19. Dua S, Bhuker M, Sharma P, Dhall M, Kapoor S: Body mass index relates to blood pressure among adults . N Am J Med Sci. 2014, 6:89-95. 10.4103/1947-2714.127751

20. Midha T, Krishna V, Nath B, Kumari R, Rao YK, Pandey U, Kaur S: Cut-off of body mass index and waist circumference to predict hypertension in Indian adults. World J Clin Cases. 2014, 2:272-8. 10.12998/wjcc.v2.i7.272

21. Huang G, Xu JB, Zhang TJ, et al.: Prevalence, awareness, treatment, and control of hypertension among very elderly Chinese: results of a community-based study. J Am Soc Hypertens. 2017, 11:503-512.e2. 10.1016/j.jash.2017.05.008

22. Tesfaye F, Nawi NG, Van Minh H, Byass P, Berhane Y, Bonita R, Wall S: Association between body mass index and blood pressure across three populations in Africa and Asia. J Hum Hypertens. 2007, 21:28-37. 10.1038/sj.jhh.1002104

23. Kim NY, Hong YM, Jung JW, Kim NS, Noh CI, Song YH: The relationships of body mass index, waist-toheight ratio, and body fat percentage with blood pressure and its hemodynamic determinants in Korean adolescents: a school-based study. Korean J Pediatr. 2013, 56:526-33. 10.3345/kjp.2013.56.12.526

24. Waterland RA, Garza C: Potential mechanisms of metabolic imprinting that lead to chronic disease . Am J Clin Nutr. 1999, 69:179-97. 10.1093/ajcn/69.2.179

25. Song YH: The association of blood pressure with body mass index and waist circumference in normal weight and overweight adolescents. Korean J Pediatr. 2014, 57:79-84. 10.3345/kjp.2014.57.2.79

26. Tawfik HM: Waist height ratio and waist circumference in relation to hypertension, Framingham risk score in hospitalized elderly Egyptians. Egypt Heart J. 2018, 70:213-6. 10.1016/j.ehj.2017.12.008

27. Florêncio TT, Ferreira HS, Cavalcante JC, Stux GR, Sawaya AL: Short stature, abdominal obesity, insulin resistance and alterations in lipid profile in very low-income women living in Maceió, north-eastern Brazil. Eur J Cardiovasc Prev Rehabil. 2007, 14:346-8. 10.1097/hjr.0b013e328010f24d

28. Choi JR, Koh SB, Choi E: Waist-to-height ratio index for predicting incidences of hypertension: the ARIRANG study. BMC Public Health. 2018, 18:767. 10.1186/s12889-018-5662-8

29. Nagar SR, Jain M: Study to assess predictive value of waist to height ratio and body mass index as a risk factor of hypertension and type 2 diabetes mellitus. Int J Community Med Public Health. 2017, 4:1099-10. 10.18203/2394-6040.ijcmph20171331

30. Caminha TC, Ferreira HS, Costa NS, Nakano RP, Carvalho RE, Xavier AF Jr, Assunção ML: Waist-to-height ratio is the best anthropometric predictor of hypertension: a population-based study with women from a state of northeast of Brazil. Medicine (Baltimore). 2017, 96:e5874. 10.1097/MD.0000000000005874 